\title{
Predictive Modeling of Hypoglycemia for Clinical Decision Support in Evaluating Outpatients with Diabetes Mellitus
}

Xiaochun Li, PhD, ${ }^{1}$ Shengsheng Yu, $\mathrm{PhD},{ }^{2}$ Zuoyi Zhang, $\mathrm{PhD},{ }^{3}$ Larry Radican, $\mathrm{PhD}, \mathrm{MPH},{ }^{2}$

Jonathan Cummins, MS, ${ }^{3}$ Samuel S. Engel, MD, ${ }^{2}$ Kristy Iglay, $\mathrm{PhD},{ }^{2}$ Jon Duke, MD, MS,,${ }^{1,3}$ Jarod Baker, MS, ${ }^{3}$ Kimberly G. Brodovicz, DrPH, ${ }^{2}$

Ramachandra G. Naik, MD, DM, ${ }^{2}$ Jeremy Leventhal, MS, ${ }^{3}$ Arnaub K. Chatterjee, MHA, MPA, ${ }^{2}$ Swapnil Rajpathak, MBBS, DrPH, ${ }^{2}$ Michael Weiner, MD, MPH, ${ }^{1,3,4}$

${ }^{1}$ Indiana University, Indianapolis, IN

${ }^{2}$ Merck \& Co., Inc., Kenilworth, NJ

${ }^{3}$ Regenstrief Institute, Inc., Indianapolis, IN

${ }^{4}$ Center for Health Information and Communication, Department of Veterans Affairs, Veterans Health Administration, Health Services Research and Development Service CIN 13-416, Richard L. Roudebush VA Medical Center, Indianapolis, IN

Corresponding author:

Xiaochun Li, Ph.D. < mailto:xiaochun@iu.edu $>$

Department of Biostatistics

410 West Tenth Street, suite 3000

Indianapolis, Indiana 46202

U.S.A.

$\mathrm{Ph}+1$ 317-274-2661

Key words: Hypoglycemia; Diabetes Mellitus; Predictive Value of Tests

This is the author's manuscript of the article published in final edited form as:

Li, X., Yu, S., Zhang, Z., Radican, L., Cummins, J., Engel, S. S., Iglay, K., Duke, J., Baker, J., Brodovicz, K. G., Naik, R. G., Leventhal, J., Chatterjee, A. K., Rajpathak, S., \& Weiner, M. (2019). Predictive modeling of hypoglycemia for clinical decision support in evaluating outpatients with diabetes mellitus. Current Medical Research and Opinion, 35(11), 1885-1891. 


\section{ABSTRACT}

Objective. Hypoglycemia occurs in $20 \%$ to $60 \%$ of patients with diabetes mellitus. Identifying at-risk patients can facilitate interventions to lower risk. We sought to develop a hypoglycemia prediction model.

Methods. In this retrospective cohort study, urban adults prescribed a diabetes drug between 2004 and 2013 were identified. Demographic and clinical data were extracted from an electronic medical record (EMR). Laboratory tests, diagnostic codes, and natural language processing (NLP) identified hypoglycemia. We compared multiple logistic regression, classification and regression trees (CART), and Random Forest. Models were evaluated on an independent test set or through cross-validation.

Results. 38,780 patients had mean age 57 years; 56\% were female, 40\% African-American, and 39\% uninsured. Hypoglycemia occurred in 8,128 (539 identified only by NLP). In logistic regression, factors positively associated with hypoglycemia included infection, non-long-acting insulin, dementia, and recent hypoglycemia. Negatively associated factors included long-acting insulin plus sulfonylurea, and age 75 or older. Models' area under curve was similar (logistic regression, 89\%; CART, 88\%; Random Forest, 90\%, with 10-fold cross-validation). Conclusions. NLP improved identification of hypoglycemia. Non-long-acting insulin was an important risk factor. Decreased risk with age may reflect treatment or diminished awareness of HG. More complex models did not improve prediction. 


\section{INTRODUCTION}

Diabetes mellitus is one of the most common non-communicable diseases worldwide and a major cause of morbidity and mortality [1]. An estimated 422 million people had diabetes in 2014, and diabetes is predicted to become the seventh leading cause of death in the world by the year 2030 [2]. The number of people with type 2 diabetes mellitus (T2DM), the most common form of diabetes, is increasing in every country [1]. In the United States, the incidence of diabetes nearly tripled between 1990 and 2010 [3], and 1.7 million new cases were diagnosed in adults in 2012 [4]. Among Americans 65 or more years of age, the prevalence is $26 \%$ [4].

Hypoglycemia (HG) is recognized as the major limiting factor in optimal glycemic management for patients with diabetes [5 6]. Substantial negative effects on cardiovascular safety and quality of life have been noted [7-12]. It also increases economic costs, which result from healthcare resource utilization to manage $\mathrm{HG}$ and its consequences, as well as from patient absenteeism and lost productivity [13]. Many patients with diabetes, especially those with recurring episodes of $\mathrm{HG}$, are unaware when $\mathrm{HG}$ occurs, despite the risk of serious adverse events including coma and death. Identifying patients at especially high risk of HG may provide an opportunity to intervene and reduce the incidence of events. Using electronic medical records and computer-based algorithms to identify HG is challenging, because diagnostic codes for $\mathrm{HG}$ are not consistently used, and are subject to underreporting. Signs or symptoms of specific episodes of HG, especially if not severe, might be recorded only in an unstructured, narrative (text-based) format.

In this study, based on existing literature about HG risk, we developed a multivariable HG risk model for use in clinical practice by physicians and other health care professionals. Our goal in this analysis was to compare three popular models of prediction, applying them to HG using data 
routinely collected in an electronic health record system, and decide on one for implementation of clinical decision support. This would be the first HG model that combines nearly all known risk factors among U.S. outpatients. 


\section{METHODS}

This retrospective study was approved, with a waiver of informed consent, by the Indiana University Institutional Review Board, protocol number 1402826879.

\section{1 design}

In this retrospective cohort study, the study period was defined to be 01 January 2004 to 31 December 2013. Eskenazi Health is an urban safety-net medical institution [14] in Indianapolis, Indiana, U.S.A. In 2012, Eskenazi had 1,081 physicians on staff and serviced 950,592 outpatient visits, including 234,637 community health center visits. The payer mix was $38 \%$ uninsured, 32\% Medicaid, 19\% Medicare, $8 \%$ commercial, and 3\% other. The Indiana Network for Patient Care is a statewide network of electronic medical data, representing 25,000 physicians, 106 hospitals, and 110 clinics, surgery centers, and other healthcare organizations, including Eskenazi Health. The network includes information "from encounters covering over 90\% of care provided at hospitals in the Indianapolis area", including abstracts, text reports, discharge summaries, operative notes, pathology reports, electrocardiogram readings, radiology images, and medication records [15 16] The study cohort consisted of patients who received outpatient care at Eskenazi during the study period, as identified through computer-based query of the network. The study targeted electronic medical data in retrospective analysis; patients were not contacted. Clinical data about the cohort were extracted from the Regenstrief Medical Record System, an electronic health record system used by Eskenazi Health [17].

HG events were identified among the cohort. The index date was defined as the first date of HG during the study period that occurred at least two years after the patient's first encounter between January 2002 and December 2011. For patients in this cohort who did not experience a HG event 
during the study period, the index date was a randomly selected date of an actual visit during the study period. The baseline period was defined as the two-year period prior to the index date. Eligible patients were selected from the cohort if they met the following inclusion criteria: at least 21 years of age at the index date, prescribed or dispensed a drug for diabetes mellitus during the study period, and had at least two clinical encounters on separate dates during the baseline period. Drugs for diabetes were acarbose, acetohexamide, alogliptin, canagliflozin, chlorpropamide, colesevelam, dapagliflozin, exenatide, glibenclamide, glimepiride, glipizide, glyburide, insulin, linagliptin, liraglutide, meglitol, metformin, nateglinide, pioglitazone, pramlintide, repaglinide, rosiglitazone, saxagliptin, sitagliptin, tolazamide, and voglibose. We did not attempt to identify a subgroup of patients with type 1 diabetes since administrative data are not always reliable in distinguishing types of diabetes. Baseline covariates (predictors; see

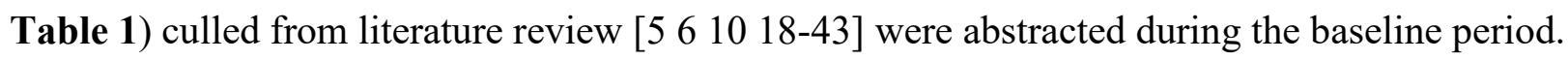
Medical conditions were identified by diagnostic codes in medical records. Based on previous studies, glomerular filtration rate [34], infection [34] within 30 days, and serum calcium [42] were included. See the Appendix for a listing of diagnosis and procedure codes corresponding to conditions.

\begin{tabular}{ccc}
\hline Table 1. Patients' characteristics and baseline \\
\multicolumn{3}{c}{ covariates $(\mathbf{N}=\mathbf{3 8 , 7 8 0})$} \\
Pariable & $\begin{array}{c}\text { Patients with } \\
\text { (N=38,780) }\end{array}$ & $\begin{array}{c}\text { hypoglycemia } \\
\text { (N=8128) }\end{array}$ \\
\hline Age (years) & \\
$21-44$ & 7644 & 1547 \\
$45-64$ & 20,080 & 4470 \\
$65-74$ & 6916 & 1441 \\
$75-84$ & 3238 & 559 \\
$\geq 85$ & 902 & 111 \\
Gender & & \\
Female & 21,841 & 4816 \\
Male & 16,939 & 3312
\end{tabular}




\begin{tabular}{|c|c|c|}
\hline \multicolumn{3}{|l|}{ Race } \\
\hline White & 18,355 & 2991 \\
\hline Black & 15,510 & 4439 \\
\hline Spanish & 1031 & 162 \\
\hline Native American & 934 & 218 \\
\hline Unknown & 2950 & 318 \\
\hline \multicolumn{3}{|l|}{ Insurance } \\
\hline Medicaid & 7196 & 3437 \\
\hline $\begin{array}{l}\text { Insured without } \\
\text { Medicaid }\end{array}$ & 16,571 & 2865 \\
\hline Uninsured & 15,013 & 1826 \\
\hline BMI $\left(\mathrm{kg} / \mathrm{m}^{2}\right)$ & $35.7(9.8)$ & $35.1(10.0)$ \\
\hline \multicolumn{3}{|l|}{ Alcohol } \\
\hline No & 37,919 & 7703 \\
\hline Yes & 861 & 425 \\
\hline \multicolumn{3}{|l|}{ Autonomic failure } \\
\hline No & 38,743 & 8114 \\
\hline Yes & 37 & 14 \\
\hline \multicolumn{3}{|l|}{ Cancer } \\
\hline No & 37,729 & 7587 \\
\hline Yes & 1051 & 541 \\
\hline \multicolumn{3}{|l|}{ Chronic heart failure } \\
\hline No & 37,198 & 7088 \\
\hline Yes & 1582 & 1040 \\
\hline \multicolumn{3}{|l|}{ Coronary artery disease } \\
\hline No & 36,759 & 6999 \\
\hline Yes & 2021 & 1129 \\
\hline \multicolumn{3}{|l|}{ Dementia or falls } \\
\hline No & 37,527 & 7438 \\
\hline Yes & 1253 & 690 \\
\hline \multicolumn{3}{|l|}{ Diabetic neuropathy } \\
\hline No & 37,366 & 7291 \\
\hline Yes & 1414 & 837 \\
\hline \multicolumn{3}{|l|}{ Last hospital discharge } \\
\hline $\begin{array}{l}\text { 1-30 days before index } \\
\text { date }\end{array}$ & 35,092 & 6133 \\
\hline 31-365 days & 2858 & 1470 \\
\hline$>365$ days & 830 & 525 \\
\hline \multicolumn{3}{|l|}{ Infection within 30 days } \\
\hline No & 37,395 & 7284 \\
\hline Yes & 1385 & 844 \\
\hline \multicolumn{3}{|l|}{ Last HbA1c } \\
\hline$\leq 6.5 \%$ & 5321 & 2354 \\
\hline$>6.5 \%,<7 \%$ & 1840 & 793 \\
\hline$\geq 7 \%,<8 \%$ & 3155 & 1369 \\
\hline$\geq 8 \%,<9 \%$ & 1773 & 793 \\
\hline$\geq 9 \%$ & 3977 & 1789 \\
\hline Missing & 22,714 & 1030 \\
\hline Serum calcium (mg/dL) & $9.4(0.7)$ & $9.2(0.8)$ \\
\hline
\end{tabular}




\begin{tabular}{|c|c|c|}
\hline \multicolumn{3}{|l|}{$\begin{array}{l}\text { Hypoglycemia within } 12 \\
\text { months }\end{array}$} \\
\hline No & 38,121 & 7632 \\
\hline Yes & 659 & 496 \\
\hline $\begin{array}{l}\text { Glomerular filtration } \\
\text { rate, estimated } \\
\left(\mathbf{m L} / \mathbf{m i n} / \mathbf{1 . 7 3 m ^ { 2 } )}\right.\end{array}$ & $84.7(31.7)$ & $79.2(35.9)$ \\
\hline \multicolumn{3}{|l|}{$\begin{array}{l}\text { Antibiotics within } 30 \\
\text { days, SU within } 90 \text { days }\end{array}$} \\
\hline Antibiotics and SU & 765 & 163 \\
\hline Antibiotics without SU & 2602 & 366 \\
\hline No antibiotics & 35,413 & 7599 \\
\hline \multicolumn{3}{|l|}{$\begin{array}{l}\text { Insulin and SU within } 12 \\
\text { months }\end{array}$} \\
\hline LAI without SU & 4720 & 726 \\
\hline $\begin{array}{l}\text { LAI and SU, not within } \\
90 \text { days }\end{array}$ & 66 & 11 \\
\hline $\begin{array}{l}\text { LAI and SU within } 90 \\
\text { days }\end{array}$ & 1248 & 144 \\
\hline $\begin{array}{l}\text { Non-LAI insulin without } \\
\text { SU }\end{array}$ & 3055 & 1260 \\
\hline $\begin{array}{l}\text { Non-LAI insulin and } \\
\text { SU, not within } 90 \text { days }\end{array}$ & 47 & 20 \\
\hline $\begin{array}{l}\text { Non-LAI insulin and SU } \\
\text { within } 90 \text { days }\end{array}$ & 615 & 264 \\
\hline SU without insulin & 8727 & 2079 \\
\hline No insulin, no SU & 20,302 & 3624 \\
\hline \multicolumn{3}{|c|}{$\begin{array}{l}\text { LAI = long-acting insulin, SU = sulfonylurea } \\
\text { Note: a two-year baseline window prior to the index } \\
\text { date is used for most risk factors; a one-year window for } \\
\text { prior episodes of hypoglycemia was used, and a 30-day } \\
\text { window for infections and antibiotic use. }\end{array}$} \\
\hline
\end{tabular}

\subsection{HG definition}

HG was defined by any of the following criteria.

- Plasma or point-of-care glucose value of at least $5 \mathrm{mg} / \mathrm{dL}$, and less than $70 \mathrm{mg} / \mathrm{dL}$, documented in the medical record. A minimum, positive glucose value was included to avoid spurious values of zero.

- International Classification of Diseases-9-Clinical Modification (ICD) code 251.1 or 251.2 . 
- ICD code 250.8 without any of the following codes [44]: 259.8, 272.7, 681.xx, 682.x, $686.9,707.1 \mathrm{x}, 707.2 \mathrm{x}, 707.8,707.9,709.3,730.0 \mathrm{x}, 730.1 \mathrm{x}, 730.2 \mathrm{x}, 731.8$.

- Text note indicating HG, including a glucose value.

To use NLP to evaluate text notes, we used a combination of Unstructured Information Management Architecture [45], a sentence tokenizer from the Open NLP project [46], and a regular expression system. This identified clinical reports mentioning a "blood sugar word" followed within five words by what could be a low blood-sugar value represented by a number in the range 10 to 69 . We filtered (dropped) text representing dates and times, units of weight, strings with leading "if", and strings referencing proteins, in case protein numbers were documented instead of glucose values. The regular expression for a "blood sugar word" was "(?i)(^|\b)(glucose|glu(?!cotrol)|gluc(?!otrol)|sugars|sugar|bs|bg|accucheck|accuchek|glucometer) *(,|M.|;|\$)".

\section{3 predictive modeling approaches}

We considered three predictive modeling approaches: conventional multiple logistic regression (LR), classification and regression trees (CART) [47], and Random Forest (RF) [48].

\section{Logistic Regression}

In LR, the presence or absence of $\mathrm{HG}$ (dependent variable) was modelled with all baseline covariates in the model as main effects (independent variables). Missing values of continuous variables were handled by imputing the mean of observed data. Missing values of categorical variables except demographics were set to zero/unknown or without having the condition. Forward stepwise variable selection was used for including predictors in the model, using an entry criterion of alpha at 0.10 and a stay criterion of alpha at 0.05 . Since the goal was prediction rather than explanation of the HG mechanism, we used a data-driven approach and did not force 
specific variables into the model. LR is commonly used in medical research. It requires the assumption that the relationship between the outcome and the predicting covariates is linear.

\section{Classification and Regression Trees}

Tree-based methods offer many appealing advantages over LR, a parametric modeling approach. They require no specification of the relationship of the covariates with the outcome, and approximate the relationship adaptively, driven by data. Trees can capture complex interactions among covariates, and can handle highly correlated covariates. The rank-based nature of binary splits in covariates also makes trees robust to outliers and invariant to monotonic transformations of the covariates. For example, the same predictions can be obtained whether age, $\log ($ age $)$, or age $^{2}$ is used. Trees also handle irrelevant covariates well; if a covariate does not predict the response, a tree will not include it.

From the practical perspective, a single tree enables a visual inspection of the risk of an outcome based on patients' characteristics and baseline variables, such as medication use, diagnoses, and laboratory results. Hence, it provides clinical interpretability and, if parsimonious, may be ideal for a clinical decision support tool. Trees, however, require large sample sizes for stability. The 'right-sized tree' was selected by ten-fold cross-validation.

\section{Random Forests}

The method of Random Forests generates an ensemble of trees. Tree-based ensembles combine the predictions of many different trees to give an aggregated prediction, a procedure of model averaging. The advantage of a tree ensemble over a single tree is that it maintains the low bias of a single tree but with a much lower variance, achieved through averaging. For classification trees, using such an average amounts to using the most frequently predicted class, known as the 'majority vote'. Ensembles can give improved prediction accuracy over individual trees. An 
intuitive idea behind the improved accuracy of ensemble classifiers is that if the individual classifiers tend to make prediction errors in different regions of predictor space, then the incorrect predictions may be overwhelmed by the correct ones.

One disadvantage of tree ensembles compared to a single tree is that ensembles can be difficult to interpret, because the average of trees is not a tree. Due to the intended use of our model in clinical practice, we placed significant value on accuracy of prediction.

\section{Evaluation of the Three Approaches}

The data set was randomly split into a training data set and a test data set in the ratio of 2:1. All three modeling approaches were applied to the training data set and tested on the test data set. Each model was fitted on the training set, and then was applied to the test set to predict HG events. The area under the receiver operating characteristic (ROC) curve, i.e., AUC or c-statistic, is a measure of the overall performance of a model, regardless of cutoffs. We calculated the AUC on the test set. We also estimated AUC through ten-fold cross-validation using the entire data set for the three approaches, as a consistency assurance in model selection.

\section{4 analysis}

Baseline covariates were summarized using percentages if categorical, or means with standard deviations if continuous. Multiple LR modeling was performed using SAS, version 9.4 (SAS Institute; Cary, NC); classification trees and random forests were built using R, version 3.2.0 $<\underline{\text { http://www.R-project.org/> }}$. 


\section{RESULTS}

The cohort had 38,780 patients with the following characteristics: mean age of 57 years, $56 \%$ female, 47\% white, 40\% African-American, 19\% with Medicaid, and 39\% uninsured (see Table 1). HG was identified in 8,128 (21\%) of them; a glucose value of less than $54 \mathrm{mg} / \mathrm{dL}$ was found in __. Of the 8,128 with HG, NLP identified HG in 3,751, with 539 identified only by

NLP. The median, mean, and standard deviation for number of outpatient visits in the previous year were 8,10 , and 9 , respectively.

\begin{tabular}{|c|c|c|}
\hline Variable & $\begin{array}{c}\text { Odds ratio } \\
(\mathrm{OR})\end{array}$ & $\begin{array}{c}\text { Confidence } \\
\text { interval of OR }\end{array}$ \\
\hline \multicolumn{3}{|l|}{ Age (years) } \\
\hline $21-44$ & 1.4 & $(1.3,1.5)$ \\
\hline $45-64$ & Ref. & \\
\hline $65-74$ & 0.9 & $(0.9,1.0)$ \\
\hline $75-84$ & 0.8 & $(0.7,0.9)$ \\
\hline$\geq 85$ & 0.6 & $(0.5,0.8)$ \\
\hline \multicolumn{3}{|l|}{ Gender } \\
\hline Female & 1.1 & $(1.0,1.2)$ \\
\hline Male & Ref. & \\
\hline \multicolumn{3}{|l|}{ Race } \\
\hline White & Ref. & \\
\hline Black & 1.8 & $(1.7,2.0)$ \\
\hline Spanish & 0.7 & $(0.5,0.8)$ \\
\hline Native American & 0.9 & $(0.8,1.1)$ \\
\hline Unknown & 0.8 & $(0.7,0.9)$ \\
\hline \multicolumn{3}{|l|}{ Insurance } \\
\hline Medicaid & 1.5 & $(1.4,1.6)$ \\
\hline $\begin{array}{l}\text { Insured without } \\
\text { Medicaid }\end{array}$ & Ref. & \\
\hline Uninsured & 1.0 & $(0.9,1.1)$ \\
\hline BMI $\left(\mathrm{kg} / \mathrm{m}^{2}\right)$ & 1.0 & $(1.0,1.0)$ \\
\hline \multicolumn{3}{|l|}{ Alcohol } \\
\hline No & Ref. & \\
\hline Yes & 1.6 & $(1.4,1.9)$ \\
\hline \multicolumn{3}{|l|}{ Autonomic failure } \\
\hline No & 4.1 & $(1.8,9.4)$ \\
\hline Yes & Ref. & \\
\hline
\end{tabular}




No
Yes
Chronic heart failure
No
Yes

Coronary artery disease No

Yes

Dementia or falls

No

Yes

Diabetic neuropathy

No

Yes

Last hospital discharge

1-30 days before index date

31-365 days

$>365$ days

Infection within 30 days

No

Yes

\section{Last HbA1c}

$\leq 6.5 \%$

$>6.5 \%,<7 \%$

$\geq 7 \%,<8 \%$

$\geq 8 \%,<9 \%$

$\geq 9 \%$

Missing

Serum calcium (mg/dL)

Hypoglycemia within 12 months

No

$$
\text { Yes }
$$

Glomerular filtration

rate, estimated

$\left(\mathrm{mL} / \mathrm{min} / 1.73 \mathrm{~m}^{2}\right)$

Antibiotics within 30

days, $\mathrm{SU}$ within 90 days

Antibiotics and SU

Antibiotics without SU

No antibiotics

Insulin and SU within 12 months

LAI without SU

LAI and SU, not within 90 days

LAI and SU within 90 days

Non-LAI insulin without SU
Ref.

$1.4 \quad(1.2,1.6)$

Ref.

$1.3 \quad(1.1,1.5)$

Ref.

1.2

$(1.1,1.4)$

Ref.

$1.5 \quad(1.3,1.7)$

Ref.

$1.6 \quad(1.4,1.8)$

Ref.

$1.1 \quad(1.0,1.2)$

$1.8 \quad(1.5,2.1)$

Ref.

$2.5 \quad(2.2,2.8)$

$1.1 \quad(1.0,1.2)$

Ref.

$1.0 \quad(0.9,1.1)$

$1.0 \quad(0.9,1.2)$

$1.1 \quad(0.9,1.2)$

$0.3 \quad(0.2,0.3)$

$0.5 \quad(0.5,0.5)$

Ref.

$2.4 \quad(1.9,2.9)$

$1.0 \quad(1.0,1.0)$

$1.1 \quad(0.8,1.4)$

Ref.

$1.2 \quad(1.1,1.4)$

$1.1 \quad(0.9,1.2)$

$1.5 \quad(0.7,3.2)$

$0.7 \quad(0.6,0.9)$

$2.2 \quad(2.0,2.5)$ 
Non-LAI insulin and

SU, not within 90 days

Non-LAI insulin and SU

within 90 days

SU without insulin

No insulin, no SU
1.0

Ref.
$(0.6,2.7)$

$(1.5,2.2)$

$(1.0,1.1)$

$\mathrm{LAI}=$ long-acting insulin, $\mathrm{SU}=$ sulfonylurea

Note: logistic regression was run on the entire cohort with missing data imputed by mean of observed data.

In LR, factors positively associated with HG included the following (Table 2): infection within 30 days prior to event (OR 2.5; 95\% CI 2.2, 2.8), insulin other than long-acting insulin (without SU drug, 2.2; 2.0, 2.5; with SU within 90 days, 1.8; 1.5, 2.2; vs. non-insulin and non-SU), previous hypoglycemia within 12 months $(2.4 ; 1.9,2.9)$, African-American $(1.8 ; 1.7,2.0$; vs. white), diabetic neuropathy $(1.6 ; 1.4,1.8)$, Medicaid $(1.5 ; 1.4,1.6)$, alcohol consumption (1.6; 1.4, 1.9), chronic heart failure $(1.3 ; 1.1,1.5)$, no antibiotics within 30 days $(1.2 ; 1.1,1.4)$, age 21 to $44(1.4 ; 1.3,1.5 ;$ vs. age 45 to 64$)$, and dementia or falls $(1.5 ; 1.3,1.7)$. Factors negatively associated with HG included serum calcium mg/dL (OR 0.5; 95\% CI 0.5, 0.5), age 85 years or more $(0.6 ; 0.5,0.8$; vs. age 45 to 64$)$, long-acting insulin plus an SU within 90 days $(0.7 ; 0.6$, $0.9)$, Hispanic $(0.7 ; 0.5,0.8)$, and age 75 to 84 years $(0.8 ; 0.7,0.9)$. The addition of NLP changed the statistical significance of coronary artery disease in the LR: the confidence interval was 1.0 to 1.3 without NLP, and 1.1 to 1.4 with NLP.

Performance was similar across the three models: using the ten-fold cross validation, Random Forest has a mean AUC 90\%, LR has a mean AUC 89\%, and CART a mean AUC 88\%. The AUCs of the three models when applied to the held-out independent test set, in the 2:1 random split of training and test sets, are $90 \%, 89 \%$ and $87 \%$, almost identical to the above from the tenfold cross validation. 



\section{DISCUSSION}

We developed a new predictive model of HG risk among outpatients with diabetes, comparing three statistical methods. We observed that LR, CART, and Random Forest have similar performance in our data set. The lack of advantage of tree-based methods such as CART and Random Forest over LR could be due to the following: all of our covariates are binary or categorical, except glomerular filtration rate, body mass index, and serum calcium; or possible lack of interaction between covariates. Adaptive modeling of non-linear relationships between continuous predictors and an outcome, and adaptive modeling of the interactions among predictors, are the two primary advantages of tree-based methods in comparison with conventional LR and, in general, all parametric regressions. If the linearity assumption is met and there are no interactions between covariates, tree-based methods are at a disadvantage compared to LR because they afford flexibility at the price of efficiency (i.e., having higher variance), especially when flexibility may not be needed.

From the standpoint of clinical care, the implications of this study are important. In developing a HG predictive risk model for clinical decision support, a complex predictive model does not need to be built for electronic health record data where most variables are binary or categorical. Instead, a conventional multiple LR model can be successfully employed. The LR model is commonly used in medical research and its coefficients are interpretable as odds ratios when exponentiated - a useful feature for clinicians and patients who seek to understand the relevance and magnitude of each factor. Furthermore, a LR model has the additional benefit of being straightforward to program into a risk calculator, without needing specialized software. 
Despite the advancement in pharmaceutical therapy, HG remains one of the biggest complicating factors in diabetes management. Although previous work over decades has identified many risk factors for $\mathrm{HG}$, this is the first model that combines nearly all known risk factors among U.S. outpatients in a primary-care setting, which may afford opportunities to change long-term practice and introduce educational or self-management strategies for patients, to lower the risk of HG. Several other studies that identified risk factors for HG have not used statistical models [49], or focused primarily on subgroups of patients with diabetes, such patients with Medicaid [50], hospitalization [34 38], additional cardiovascular risk factors [51], self-reported HG [35], severe HG [40], symptomatic HG [25], and use of only injectable drugs for diabetes [20]. One of our own previous studies examined the association between HG, inpatient death, and inpatient length of stay among patients treated with insulin [52]. Our present study is designed to use electronic health record data in a way that targets all adults with diabetes and HG-except perhaps the mildest cases of HG, when glucose levels might not have been measured — because electronic health record systems create the capacity for decision support, and intervention is warranted in all instances of HG in any patient with diabetes, regardless of type, severity, and symptoms.

NLP usefully complemented diagnostic codes and laboratory data in identifying HG, uniquely identifying 6.6\% (539/8128) of cases of HG. Although the percentage is modest, each case of prevented HG can improve quality of life, morbidity, and costs. Our study did not examine multiplicity of HG events per patient, but this, too, would be important. The importance of NLP in this outpatient context is not surprising, because many cases of HG occur when patients are at home or otherwise away from the medical institution, without a laboratory test to confirm the condition. We are aware of no previous work that incorporates NLP into a statistical model of 
HG. We did not have direct access to glucometer data in this study, but some glucometers have capabilities to transfer their stored data electronically, paving the way for improved communication with healthcare providers, and control of diabetes.

Our study confirmed many risk factors for HG while elucidating more detail about their magnitude in a multivariate model. Insulin other than long-acting insulin was an important risk factor without a sulfonylurea drug, or with a sulfonylurea drug within 90 days. Although some newer oral drugs for diabetes lead to HG less frequently, therapeutic inertia and other factors have led to a slow transition to newer drugs for many patients. In light of newer and possibly safer drugs, weighing the potential benefits and harms of sulfonylurea drugs is increasingly important.

We were surprised to find that the oldest ages (age $\geq 75$ years) were at a decreased risk for HG events, though Duran-Nah et al. reported this, too [25]. The finding may reflect diminished awareness of $\mathrm{HG}$, greater attention to medical management (i.e., less aggressive management as a result of attention to clinical guidelines for older patients), or other unmeasured factors in this population.

Since we targeted patients in a safety-net institution, the results might not be generalizable to other populations. We used diagnostic (ICD) codes to identify many of the covariate conditions, but these codes have imperfect sensitivity and specificity. Nonetheless, their usage reflects realworld application that may transfer to other settings. We would not have captured the mildest cases of HG, since they might not be documented anywhere in the medical record. In this study, any HG, rather than severity of HG, was the outcome of interest due to the need for clinical 
intervention for HG. We did not examine C-peptide levels, duration of diabetes, use of home or continuous glucometry, or frequency of glucose measurement, any of which may be associated with outcomes.

In summary, starting from a large set of known HG risk factors, we created a predictive risk model for HG using conventional LR and found that more complex models did not improve prediction appreciably. Given its frequent use in the medical field and its interpretability, LR is a feasible and potentially useful method for developing a clinical decision support tool for identifying HG risk in patients with type 2 diabetes. Clinicians could use these findings to identify and address important modifiable risk factors. Such a tool could be used by electronic health record systems, to automate the retrieval and presentation of risk factors for clinicians during medical encounters with patients with diabetes. This may lead to immediate counseling of patients or changes to medical practices in pursuit of addressing the risk factors. 


\section{TRANSPARENCY}

Funding. Funding for this research was provided by Merck \& Co., Inc., Kenilworth, NJ USA. Authors affiliated with Merck assisted in designing the study, interpreting findings, and reviewing and editing the manuscript.

Relationships. Shengsheng Yu, Larry Radican, Samuel S. Engel, Kristy Iglay, Kimberly G. Brodovicz, Ramachandra G. Naik, Arnaub K. Chatterjee, and Swapnil Rajpathak are or were full-time employees of Merck \& Co. Inc., Kenilworth, NJ, USA at the time of the analysis and may own stock or hold stock options in the company. The following co-authors subsequently moved to other institutions: Larry Radican (Peloton Advantage, Parsippany, NJ), Ramachandra G. Naik (SUNY Upstate Medical University, Syracuse, NY), Kimberly G. Brodovicz (Boehringer Ingelheim Pharmaceuticals, Inc., Ridgefield, CT), and Shengsheng Yu (Abbott Diabetes Care, Alameda, CA). Xiaochun Li, Zuoyi Zhang, Jonathan Cummins, Jon Duke, Jarod Baker, Jeremy Leventhal, and Michael Weiner received research support from Merck \& Co. Inc., Kenilworth, NJ, USA for the conduct of this study.

Authors' contributions. XL, SY, LR, SE, JD, KB, RN, JL, AC, SR, and MW designed the study. JC provided computer programming related to the predictive modeling. XL and ZZ conducted the analysis. All authors interpreted the findings. XL drafted the manuscript. All authors reviewed or revised the manuscript, approved the manuscript, and accepted accountability for the work.

Acknowledgements. We thank Rachel Gruber for assistance in formatting and meeting publication requirements. We thank Annaswamy Raji, MD, MMSc for feedback. Dr. Weiner is Chief of Health Services Research and Development at the Richard L. Roudebush Veterans 
Affairs Medical Center in Indianapolis, Indiana. The views expressed in this article are those of the authors and do not necessarily represent the views of Merck \& Co., Inc. or the U.S. Department of Veterans Affairs. 


\section{REFERENCES}

1. International Diabetes Federation. IDF Diabetes Atlas, 6th edn. Brussels, Belgium: International Diabetes Federation, 2013.

2. World Health Organization. Diabetes fact sheet, March 2016. Web. Accessed May 08. http://www.who.int/mediacentre/factsheets/fs312/en/.

3. Centers for Disease Control and Prevention. National diabetes fact sheet: national estimates and general information on diabetes and prediabetes in the United States, 2011. Atlanta, GA: U.S. Department of Health and Human Services, Centers for Disease Control and Prevention, 2011.

4. Centers for Disease Control and Prevention. National Diabetes Statistics Report, 2014. Atlanta, GA: U.S. Department of Health and Human Services, Centers for Disease Control and Prevention, 2014.

5. Briscoe VJ, Davis SN. Hypoglycemia in type 1 and type 2 diabetes: physiology, pathophysiology, and management. Clinical Diabetes 2006;24(3):115-24

6. Zammitt NN, Frier BM. Hypoglycemia in Type 2 Diabetes Pathophysiology, frequency, and effects of different treatment modalities. Diabetes Care 2005;28(12):2948-61

7. Vexiau P, Mavros P, Krishnarajah G, Lyu R, Yin D. Hypoglycaemia in patients with type 2 diabetes treated with a combination of metformin and sulphonylurea therapy in France. Diabetes, obesity and metabolism 2008;10(s1):16-24

8. Shiu AT, Thompson DR, Wong RY. Quality of life and its predictors among Hong Kong Chinese patients with diabetes. Journal of clinical nursing 2008;17(5a):125-32

9. Goto A, Arah OA, Goto M, Terauchi Y, Noda M. Severe hypoglycaemia and cardiovascular disease: systematic review and meta-analysis with bias analysis. BMJ: British Medical Journal 2013;347

10. Hsu P-F, Sung S-H, Cheng H-M, et al. Association of Clinical Symptomatic Hypoglycemia With Cardiovascular Events and Total Mortality in Type 2 Diabetes A nationwide population-based study. Diabetes care 2013;36(4):894-900

11. Lundkvist J, Berne C, Bolinder B, Jönsson L. The economic and quality of life impact of hypoglycemia. The European Journal of Health Economics 2005;6(3):197-202

12. Davis RE, Morrissey M, Peters JR, Wittrup-Jensen K, Kennedy-Martin T, Currie CJ. Impact of hypoglycaemia on quality of life and productivity in type 1 and type 2 diabetes. Current Medical Research and Opinion ${ }^{\circledR} 2005 ; 21(9): 1477-83$

13. Jönsson L, Bolinder B, Lundkvist J. Cost of hypoglycemia in patients with Type 2 diabetes in Sweden. Value in health 2006;9(3):193-98

14. Institute of Medicine Committee on the Changing Market, Managed Care, and the Future Viability of Safety Net Providers. America's health care safety net: intact but endangered. Washington, DC: National Academy Press, 2000.

15. Indiana Health Information Exchange. Indiana Network For Patient Care. Web. Accessed 08 May 2016. http://www.ihie.org/indiana-network-for-patient-care.

16. McDonald CJ, Overhage JM, Barnes M, et al. The Indiana network for patient care: a working local health information infrastructure. An example of a working infrastructure collaboration that links data from five health systems and hundreds of millions of entries. Health Aff (Millwood) 2005;24(5):1214-20 doi: 10.1377/hlthaff.24.5.1214[published Online First: Epub Date]|. 
17. Duke JD, Morea J, Mamlin B, et al. Regenstrief Institute's Medical Gopher: a nextgeneration homegrown electronic medical record system. Int J Med Inform 2014;83(3):170-9 doi: 10.1016/j.ijmedinf.2013.11.004[published Online First: Epub Date]|.

18. Amiel SA, Dixon T, Mann R, Jameson K. Hypoglycaemia in Type 2 diabetes. Diabetic medicine : a journal of the British Diabetic Association 2008;25(3):245-54 doi: 10.1111/j.1464-5491.2007.02341.x[published Online First: Epub Date]|.

19. Banarer S, Cryer PE. Hypoglycemia in type 2 diabetes. The Medical clinics of North America 2004;88(4):1107-16, xii-xiii doi: 10.1016/j.mcna.2004.04.003[published Online First: Epub Date]|.

20. Bramlage P, Gitt AK, Binz C, Krekler M, Deeg E, Tschope D. Oral antidiabetic treatment in type-2 diabetes in the elderly: balancing the need for glucose control and the risk of hypoglycemia. Cardiovascular diabetology 2012;11:122 doi: 10.1186/1475-2840-11122[published Online First: Epub Date]|.

21. Burge MR, Zeise TM, Sobhy TA, Rassam AG, Schade DS. Low-dose ethanol predisposes elderly fasted patients with type 2 diabetes to sulfonylurea-induced low blood glucose. Diabetes Care 1999;22(12):2037-43

22. Cryer PE, Childs BP. Negotiating the barrier of hypoglycemia in diabetes. Diabetes Spectrum 2002;15(1):20-27

23. Davis S, Alonso MD. Hypoglycemia as a barrier to glycemic control. Journal of Diabetes and its Complications 2004;18(1):60-68

24. Duckworth W, Abraira C, Moritz T, et al. Glucose control and vascular complications in veterans with type 2 diabetes. The New England journal of medicine 2009;360(2):129-39 doi: 10.1056/NEJMoa0808431[published Online First: Epub Date]|.

25. Duran-Nah JJ, Rodriguez-Morales A, Smitheram J, Correa-Medina C. Risk factors associated with symptomatic hypoglycemia in type 2 diabetes mellitus patients. Revista de investigacion clinica; organo del Hospital de Enfermedades de la Nutricion 2008;60(6):451-8

26. Group AS, Gerstein HC, Miller ME, et al. Long-term effects of intensive glucose lowering on cardiovascular outcomes. The New England journal of medicine 2011;364(9):818-28 doi: 10.1056/NEJMoa1006524[published Online First: Epub Date]|.

27. Advance Collaborative Group, Patel A, MacMahon S, et al. Intensive blood glucose control and vascular outcomes in patients with type 2 diabetes. The New England journal of medicine 2008;358(24):2560-72 doi: 10.1056/NEJMoa0802987[published Online First: Epub Date]|.

28. Action to Control Cardiovascular Risk in Diabetes Study Group, Gerstein HC, Miller ME, et al. Effects of intensive glucose lowering in type 2 diabetes. The New England journal of medicine 2008;358(24):2545-59 doi: 10.1056/NEJMoa0802743 [published Online First: Epub Date]|.

29. Guisasola FA, Povedano ST, Krishnarajah G, Lyu R, Mavros P, Yin D. Hypoglycaemic symptoms, treatment satisfaction, adherence and their associations with glycaemic goal in patients with type 2 diabetes mellitus: findings from the Real-Life Effectiveness and Care Patterns of Diabetes Management (RECAP-DM) Study. Diabetes, Obesity and Metabolism 2008;10(s1):25-32

30. The Diabetes Control and Complications Trial Research Group. The effect of intensive treatment of diabetes on the development and progression of long-term complications in 
insulin-dependent diabetes mellitus. The New England journal of medicine 1993;329(14):977-86 doi: 10.1056/NEJM199309303291401[published Online First: Epub Date]|.

31. Gibson EM, Tingen MS. Nursing care for diabetic patients with alcohol-induced hypoglycemia. Journal of emergency nursing: JEN : official publication of the Emergency Department Nurses Association 1998;24(2):165-8

32. Holman RR, Thorne KI, Farmer AJ, et al. Addition of biphasic, prandial, or basal insulin to oral therapy in type 2 diabetes. New England Journal of Medicine 2007;357(17):1716-30

33. Kirkman MS, Briscoe VJ, Clark N, et al. Diabetes in older adults: a consensus report. Journal of the American Geriatrics Society 2012;60(12):2342-56 doi: 10.1111/jgs.12035[published Online First: Epub Date].

34. Lin YY, Hsu CW, Sheu WH, Chu SJ, Wu CP, Tsai SH. Risk factors for recurrent hypoglycemia in hospitalized diabetic patients admitted for severe hypoglycemia. Yonsei medical journal 2010;51(3):367-74 doi: 10.3349/ymj.2010.51.3.367[published Online First: Epub Date]|.

35. Lipska KJ, Warton EM, Huang ES, et al. HbAlc and risk of severe hypoglycemia in type 2 diabetes: the Diabetes and Aging Study. Diabetes Care 2013;36(11):3535-42 doi: 10.2337/dc13-0610[published Online First: Epub Date]|.

36. Mohamed Z, Arya VB, Hussain K. Hyperinsulinaemic hypoglycaemia:genetic mechanisms, diagnosis and management. Journal of clinical research in pediatric endocrinology 2012;4(4):169-81 doi: 10.4274/jcrpe.821[published Online First: Epub Date]|.

37. Montori VM, Fernandez-Balsells M. Glycemic control in type 2 diabetes: time for an evidence-based about-face? Annals of internal medicine 2009;150(11):803-8

38. Quilliam BJ, Simeone JC, Ozbay AB. Risk factors for hypoglycemia-related hospitalization in patients with type 2 diabetes: a nested case-control study. Clinical therapeutics 2011;33(11):1781-91 doi: 10.1016/j.clinthera.2011.09.020[published Online First: Epub Date $]$.

39. Rodbard HW, Gough S, Lane W, Korsholm L, Bretler DM, Handelsman Y. Reduced Risk of Hypoglycemia with Insulin Degludec Versus Insulin Glargine in Patients with Type 2 Diabetes Requiring High Doses of Basal Insulin: Meta-Analysis of Five Randomized Begin Trials. Endocrine practice : official journal of the American College of Endocrinology and the American Association of Clinical Endocrinologists 2013:1-23 doi: 10.4158/ep13287.or[published Online First: Epub Date]|.

40. Samann A, Lehmann T, Heller T, et al. A retrospective study on the incidence and risk factors of severe hypoglycemia in primary care. Family practice 2013;30(3):290-3 doi: 10.1093/fampra/cms071[published Online First: Epub Date]|.

41. Schelleman H, Bilker WB, Brensinger CM, Wan F, Hennessy S. Anti-infectives and the risk of severe hypoglycemia in users of glipizide or glyburide. Clinical pharmacology and therapeutics 2010;88(2):214-22 doi: 10.1038/clpt.2010.74[published Online First: Epub Date]|.

42. Williams ME, Garg R, Wang W, Lacson R, Maddux F, Lacson E, Jr. High Hemoglobin A1c levels and glycemic variability increase risk of severe hypoglycemia in diabetic hemodialysis patients. Hemodialysis international. International Symposium on Home Hemodialysis 2013(Nov 26):1-10 doi: 10.1111/hdi.12110[published Online First: Epub Date]|. 
43. Turner R, Holman R, Cull C, et al. Intensive blood-glucose control with sulphonylureas or insulin compared with conventional treatment and risk of complications in patients with type 2 diabetes (UKPDS 33). Lancet 1998;352(9131):837-53

44. Ginde AA, Blanc PG, Lieberman RM, Camargo CA, Jr. Validation of ICD-9-CM coding algorithm for improved identification of hypoglycemia visits. BMC endocrine disorders 2008;8:4 doi: 10.1186/1472-6823-8-4[published Online First: Epub Date]|.

45. Organization for the Advancement of Structured Information Standards (OASIS). Unstructured Information Management Architecture (UIMA) Version 1.0, 02 March 2009. Web. Accessed 08 May 2016. http://docs.oasis-open.org/uima/v1.0/uimav1.0.html.

46. The Apache Software Foundation. Apache OpenNLP Developer Documentation, 2014. Web. Accessed 08 May 2016. https://opennlp.apache.org/documentation/1.6.0/manual/opennlp.html.

47. Breiman L, Freidman JH, Olshen RA, Stone DJ. Classification and Regression Trees. New York: Chapman \& Hall/CRC Press, 1984.

48. Breiman L. Random forests. Web. Accessed 18 June 2018. https://www.stat.berkeley.edu/users/breiman/randomforest2001.pdf.

49. Ben-Ami H, Nagachandran P, Mendelson A, Edoute Y. Drug-induced hypoglycemic coma in 102 diabetic patients. Archives of internal medicine 1999;159(3):281-4

50. Shorr RI, Ray WA, Daugherty JR, Griffin MR. Antihypertensives and the risk of serious hypoglycemia in older persons using insulin or sulfonylureas. JAMA : the journal of the American Medical Association 1997;278(1):40-3

51. Punthakee Z, Miller ME, Launer LJ, et al. Poor cognitive function and risk of severe hypoglycemia in type 2 diabetes: post hoc epidemiologic analysis of the ACCORD trial. Diabetes Care 2012;35(4):787-93 doi: 10.2337/dc11-1855[published Online First: Epub Date]|.

52. Brodovicz KG, Mehta V, Zhang Q, et al. Association between hypoglycemia and inpatient mortality and length of hospital stay in hospitalized, insulin-treated patients. Current medical research and opinion 2013;29(2):101-7 doi:

10.1185/03007995.2012.754744[published Online First: Epub Date]|. 


\section{APPENDIX: DIAGNOSIS AND PROCEDURE CODES}

\begin{tabular}{|c|c|}
\hline Condition & ICD code except where noted \\
\hline Adrenal insufficiency & $255.4,255.5$ \\
\hline Alcohol & 303.xx, 305.0x, 291.4, 980.0 \\
\hline Autonomic failure & $337 . \mathrm{x}$ \\
\hline Bariatric surgery & $\begin{array}{l}\text { CPT-4: } 43770,43644,43645,43842,43843,43844, \\
\text { 43845, 43846, 43847, 43659, 43770, 43771, 43772, } \\
\text { 43773, 43774, 43775, 43848, 43850, 43855, 43860, } \\
\text { 43865, 43886, 43887, 43888, S2082, S2085 } \\
\text { 278.01 plus any of the following CPT-4: } 43.89,44.31 \text {, } \\
\text { 44.38, 44.39; ICD V45.86 }\end{array}$ \\
\hline Cancer & 140.x-208.x \\
\hline Chronic heart failure & 428.x, 402.01, 402.11, 402.91, 429.4, 398.91 \\
\hline Chronic liver disease and cirrhosis & $571 . \mathrm{x}$ \\
\hline Insulin pump & $\begin{array}{l}\text { V45.85 } \\
\text { HCPCS E0784, A9274 }\end{array}$ \\
\hline Dementia or falls & $\begin{array}{l}\text { 331.0, 290.0, 290.1x, 290.2x, 290.3, 290.4x, 291.2, } \\
\text { 294.1 } \\
\text { E880.x, E881.x, E882, E883.x, E884.x, E885, E886.9, } \\
\text { E887, E888, V15.88; 781.2, 781.3 }\end{array}$ \\
\hline Depression & $\begin{array}{l}311,300.4,296.2,296.3,296.5,296.6,296.82,296.89, \\
\quad 298.0\end{array}$ \\
\hline Diabetic neuropathy & 250.6 \\
\hline Eating disorder & $307.1,307.51,307.53,307.54$ \\
\hline Hypertension & 401.x, 402.xx, 403.xx, 404.xx, 405.xx \\
\hline Hypothyroidism & $243,244 . x$ \\
\hline Infection & $\begin{array}{l}\text { 001.x-139.x, 462,480.x-487.x, 595.x, 590.xx, 681.xx, } \\
\text { 682.x, 607.2, 607.81, 607.1, 616.1 }\end{array}$ \\
\hline Ischemic heart disease & 410.xx, 411.xx, 412, 413.x, 414.xx \\
\hline Malnutrition & $263 . x, 260,261,262$ \\
\hline Panhypopituitarism & 253.2 \\
\hline Renal failure & 584.x, 585, 586, 588.x \\
\hline Stroke and cerebrovascular disease & $430-438 . x$ \\
\hline
\end{tabular}

